\title{
Attachment devices and the tarsal gland of the bug Coreus marginatus (Hemiptera: Coreidae)
}

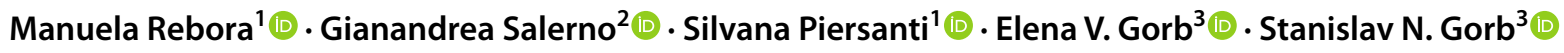

Received: 6 November 2020 / Revised: 16 December 2020 / Accepted: 18 December 2020 / Published online: 23 January 2021

(c) The Author(s) 2021

\begin{abstract}
The present ultrastructural investigation using scanning and transmission electron microscopy as well as light and fluorescence microscopy describes in detail the attachment devices and tarsal gland of the bug Coreus marginatus (L.) (Hemiptera: Coreidae). In particular, the fine structure of pulvilli reveals a ventral surface rich with pore channels, consistent with fluid emission, and a folded dorsal surface, which could be useful to enhance the pulvillus contact area during attachment to the substrate. The detailed description of the tarsal gland cells, whose structure is coherent with an active secretory function, allows us to consider the tarsal gland as the plausible candidate for the adhesive fluid production. Scolopidia strictly adhering to the gland cells are also described. On the basis of the fine structure of the tarsal gland, we hypothesise a fluid emission mechanism based on changes of the hydraulic pressure inside the gland, due to the unguitractor tendon movements. This mechanism could provide the fluid release based on compression of the pad and capillary suction, as demonstrated in other insects. The data here reported can contribute to understanding of insect adhesive fluid production, emission and control of its transport.
\end{abstract}

Keywords Insect adhesion · Adhesive fluid · Pulvilli · Claws

\section{Introduction}

Insects successfully survive in almost all ecosystems due in part to their ability to safely walk and attach to many different types of surfaces owing to the presence of claws together with smooth or hairy attachment pads on the distal portion of their legs (Beutel and Gorb 2001). Long deformable setae forming independent contacts with the substrate at numerous points (hairy pads) or soft and deformable structures with a smooth surface (smooth pads) evolved independently in different insect orders (Beutel and Gorb 2001).

Gianandrea Salerno

gianandrea.salerno@unipg.it

1 Dipartimento di Chimica, Biologia e Biotecnologie, University of Perugia, Via Elce di Sotto, 1, 06121 Perugia, Italy

2 Dipartimento di Scienze Agrarie, Alimentari e Ambientali, University of Perugia, Borgo XX Giugno, 74, 06121, Perugia, Italy

3 Department of Functional Morphology and Biomechanics, Zoological Institute, Kiel University, Am Botanischen Garten 9, 24118 Kiel, Germany
Notwithstanding a great variety of attachment devices, all insects count on a wet adhesion: indeed, in all insect groups studied so far, fluid mediates adhesion to the substrate (see review in Dirks and Federle 2011a). In both smooth and hairy attachment devices, a nanometer thin layer of fluid plays an important role in the adhesion based on both capillarity (surface tension) and viscosity principles (Edwards and Tarkanian 1970; Dixon et al. 1990; Vötsch et al. 2002; Dirks and Federle 2011a, b). Another function of the fluid is to enhance the self cleaning function of adhesive pads (Clemente et al. 2010). In spite of the numerous studies performed so far on insect adhesion, the chemical composition of the adhesive fluid in different insect orders, its exact origin, the secretion mechanism and how the secretion is controlled are still not completely elucidated (Dirks and Federle 2011a, b; Schmitt and Betz 2017).

Among different insect orders, Hemiptera and Diptera demonstrate a potential to evolve a great variety of adhesive pad designs in relation to the necessity to cling to vegetation or other substrates (Beutel and Gorb 2001). In Heteroptera, a fossula spongiosa (a hairy pad situated on the ventral surface of the distal tibia) has been described in Reduviidae (Wang and Liang 2015), smooth pseudopulvilli are present 
in Miridae (Voigt et al. 2007), while smooth pulvilli are found in members of Coreidae (Ghazi-Bayat 1979; Gorb and Gorb 2004) and Pentatomidae (Rebora et al. 2018). In particular, in Nezara viridula L. (Hemiptera: Pentatomidae), a detailed ultrastructural investigation of its attachment structures showed that they are represented by sclerotised claws, smooth flexible pulvilli and a hairy adhesive pad located at the ventral side of the basitarsus (Salerno et al. 2017; Rebora et al. 2018).

As far as the adhesive fluid production in Heteroptera is concerned, Ghazi-Bayat and Hasenfuss (1980), based only on scanning and light microscopy investigations, suggested that there are two areas secreting the adhesive fluid through the cuticle: (1) a membranous infolding at the base of the pretarsus and (2) the proximal portion of the claws. In Pentatomidae (Ghazi-Bayat and Hasenfuss 1980) and in Coreidae (Ghazi-Bayat 1979), the integumental folds on the dorsal side of the pulvilli were interpreted as a transporting system of adhesive fluid from the secretory areas to the ventral surface of pulvilli.

The present study based on scanning and transmission electron microscopy examinations describes in detail the morphology of the attachment devices with an emphasis on the ultrastructure of the tarsal gland in the bug Coreus marginatus (L.) (Hemiptera: Coreidae). The presence and distribution of resilin, an elastomeric protein, typically occurring in various regions of arthropod exoskeletons (Michels and Gorb 2012; Michels et al. 2016) and providing flexibility, resilience and enhancing adaptability of attachment pads to uneven surfaces (Perez Goodwyn et al. 2006; Peisker et al. 2013), is analysed using fluorescence light microscopy. A schematic reconstruction of the gland based on serial transversal, frontal and longitudinal semi-thin sections is also presented.

The data reported in the present study can help to shed light on the mechanisms of insect adhesive fluid production, emission and control of its transport toward the contact with the substrate.

\section{Materials and methods}

\section{Insects}

Coreus marginatus, also known as dock bug, is an important weed phytophage common in Europe, Asia and North Africa. Its favourite food is represented by leaves and seeds of species belonging to the genus Rumex, but it also feeds on a vast variety of species belonging to different families (Hrušková et al. 2005). Adult bugs were captured in the fields around Perugia, Italy. Insects were kept in a controlled condition chamber ( $14 \mathrm{~h}$ photophase, temperature of $25 \pm 1{ }^{\circ} \mathrm{C}$; relative humidity of $70 \pm 10 \%$ ), inside net cages $(30 \mathrm{~cm} \times 30 \mathrm{~cm} \times 30 \mathrm{~cm}$ ) (Vermandel, Hulst, The Netherlands). Seeds of plant species from the genus Rumex and chard (Beta vulgaris L.) leaves were used as food.

\section{Light microscopy}

To visualise the real contact area between the tarsal attachment devices and the substrate, living individuals of $C$. marginatus walking on glass were analysed with reflection contrast microscopy (RCM) using an inverted bright-field microscope ZEISS Axio Observer.A1 (Carl Zeiss Microscopy $\mathrm{GmbH}$, Jena, Germany) in combination with a highspeed camera Photron FASTCAM SA1.1 (VKT Video Kommunikation $\mathrm{GmbH}-$ Technisches Fernsehen, Pfullingen, Germany) as described earlier (Ploem 1975; Federle et al. 2002; Heepe et al. 2014).

\section{Fluorescence light microscopy}

Tarsi were cut off, mounted on cover-slips in a water-soluble medium (Moviol), and observed in a fluorescence microscope Zeiss Axioplan (Carl Zeiss Microscopy GmbH, Jena, Germany) in one of the three bands of wavelengths: green (excitation 512-546 nm, emission 600-640 nm), red (excitation $710-775 \mathrm{~nm}$, emission $810-890 \mathrm{~nm}$ ), and UV bands (excitation $340-380 \mathrm{~nm}$, emission $425 \mathrm{~nm}$ ). It is known that an insect cuticle has a strong autofluorescence at the variety of wavelengths from the blue-green area to deep-red. However, resilin has an autofluorescence at the very narrow band of wavelengths (ca. $400 \mathrm{~nm}$ ) (Andersen and Weis-Fogh 1964). Such behaviour of this protein makes it possible to reveal it in biologically native structures without immune labelling and other treatments (Gorb 1999). Exoskeleton structures that are blue in the overlay micrographs are composed of large proportions of the soft and very elastic protein resilin, while green exoskeleton structures in the overlay micrographs are chitinous and non- or weakly sclerotised, and red exoskeleton structures in the overlay micrographs are chitinous and strongly sclerotised.

Observations of the tarsal gland filled with fluorescein disodium salt (acid yellow 73, Alquera Ciencia, Spain) (Fig. 11c) were performed with a fluorescence microscope Zeiss Axiophot (Carl Zeiss Microscopy GmbH, Jena, Germany) with an excitation filter 450-490, chromatic beam splitter FT 510, emission 520. The gland was injected (the simple contact enabled injection) using a glass capillary ( $1.5 \mathrm{~mm}$ o.d, $0.9 \mathrm{~mm}$ i.d), filled with fluorescein disodium salt solution (15 mg salt in $10 \mathrm{ml}$ of distilled water). The 
capillary tubes were drawn to a fine point using a microelectrode puller (Narishige PC-10, Narishige International Ltd., London, U.K.) to get a tip less than $0.3 \mathrm{~mm}$ in diameter. The capillary insertion (Fig. 11b) was controlled with a micromanipulator HS6 (Märzhäuser Wetzlar, Wetzlar, Germany) equipped with a MCL3 controller (Lang GmbH \& Co. KG, Hüttenberg, Germany).

\section{Transmission electron microscopy}

The tarsi of ten adults were dissected from anaesthetised bugs and fixed for $12 \mathrm{~h}$ in $2.5 \%$ glutaraldehyde in cacodylate buffer (Electron Microscopy Sciences), pH 7.2. The fixed tarsi were repeatedly rinsed in sodium cacodylate buffer and post-fixed for $1 \mathrm{~h}$ at $4{ }^{\circ} \mathrm{C}$ in $1 \%$ osmium tetroxide in sodium cacodylate buffer (Electron Microscopy Sciences). The samples were then repeatedly washed in the same buffer, dehydrated using ascending ethanol concentrations and finally embedded in an Epon-Araldite resin mixture (Sigma-Aldrich). Afterwards, semi-thin and ultra-thin sections were cut using a Leica EM UC6 ultramicrotome (Leica Microsystem GmbH, Wetzlar, Germany). Serial semi-thin sections of the last tarsomere cut longitudinally, frontally and transversally, examined with a Leica DMLB light microscope (Leica Microsystem $\mathrm{GmbH}$, Wetzlar, Germany), allowed to describe in detail the gland structure. Ultra-thin sections were collected on Parlodion (Spi-Chem, West Chester, PA, U.S.A.) coated copper grids, stained with uranyl acetate and lead citrate (Electron Microscopy Sciences) and inspected in a Tecnai G2 Spirit BioTWIN transmission electron microscope (FEI Company, Hillsboro, OR, U.S.A.) operated at $80 \mathrm{kV}$. Images were acquired with a bottom-mount $4 \mathrm{k} \times 4 \mathrm{k} C D D$ Eagle camera equipped with the TEM Imaging \& Analysis (TIA) software (FEI, now Thermo Fisher Scientific Inc., Waltham, MA, USA). Additionally, ultra-thin sections mounted on the TEM grids were coated with carbon-platinum at an angle of about $15^{\circ}$ to contrast surface relief and examined in SEM or TEM.

\section{Scanning electron microscopy (SEM)}

For scanning electron microscopy, the tarsi were carefully cut off, air dried, sputter coated with gold-palladium, and observed in a Hitachi S-800 (Hitachi Ltd. Corporation, Tokyo, Japan) scanning electron microscope (SEM) at $20 \cdot \mathrm{kV}$.

To obtain 3D images of inner structures from semi-thin sections, the sections $(0.5-2.0 \mathrm{~mm})$ of the cuticle fixed and embedded as for TEM procedure were prepared using a diamond knife. Sections were picked up on pioloform-covered glass plates, treated with Maxwell's solution (Maxwell 1978) for 2-5 min to remove the resin, washed, dehydrated, and critical point dried. All preparations were mounted on holders, sputter coated with gold-palladium $(10 \mathrm{~nm})$ and examined in a Hitachi S-800 SEM at $20 \mathrm{kV}$.

\section{Cryo-scanning electron microscopy (Cryo-SEM)}

Liquid-nitrogen shock-frozen samples of the bug tarsi at various configurations were studied using a scanning electron microscope Hitachi S-4800 (Hitachi High-Technologies Corp., Tokyo, Japan) equipped with a Gatan ALTO 2500 cryo-preparation system (Gatan Inc., Abingdon, UK). For details of the sample preparation and the mounting for cryoSEM analyses, see Gorb and Gorb (2009). Whole-mount specimens were sputter coated in frozen conditions with gold-palladium (10 nm thickness) and examined at an acceleration voltage of $3 \mathrm{kV}$ and a temperature of $-120^{\circ} \mathrm{C}$ at the cryo-stage of the SEM.

\section{Results}

The tarsus of the adult of Coreus marginatus is constituted of three tarsomeres (the three sclerotised tubes of the tarsus are ring sclerites of the tarsal segment and they cannot be considered true segments as they do not bear muscle attachments) plus the pretarsal complex (Fig. 1a). The attachment devices are represented by an unpaired hairy pad and by paired pretarsal claws and pulvilli. The hairy pad is located on the ventral side of the first tarsomere (Fig. 1a). The adhesive setae of the hairy pad are socketed and have a blunt tip when observed with cryo-SEM (Fig. 1b), while they are curled when air-dried and observed with SEM (thus revealing the high flexibility of their tips) (Fig. 1c). The pulvilli are smooth pads with rather smooth ventral surface and a grooved dorsal side (Fig. 1d, e). At the level of its basal portion, the basipulvillus, each pulvillus is connected with the ipsilateral claw (Fig. 1f). An unguitractor plate is situated on the ventral side of the pretarsus and is characterised by distally oriented microplates and bears two distal paraempodia (Fig. 1f, g). The plate is surrounded by a lamina connected with the basipulvilli and the claws (Fig. 1f). The unguitractor plate with its lamina is visible, when the muscle retractor unguis (with its tendon) is relaxed (Fig. 1f), while the unguitractor plate is retracted inside the tarsus and not visible, when the muscle is contracted (Fig. 1g). When the muscle and tendon are relaxed, the claws and pulvilli are straight and aligned, while when 

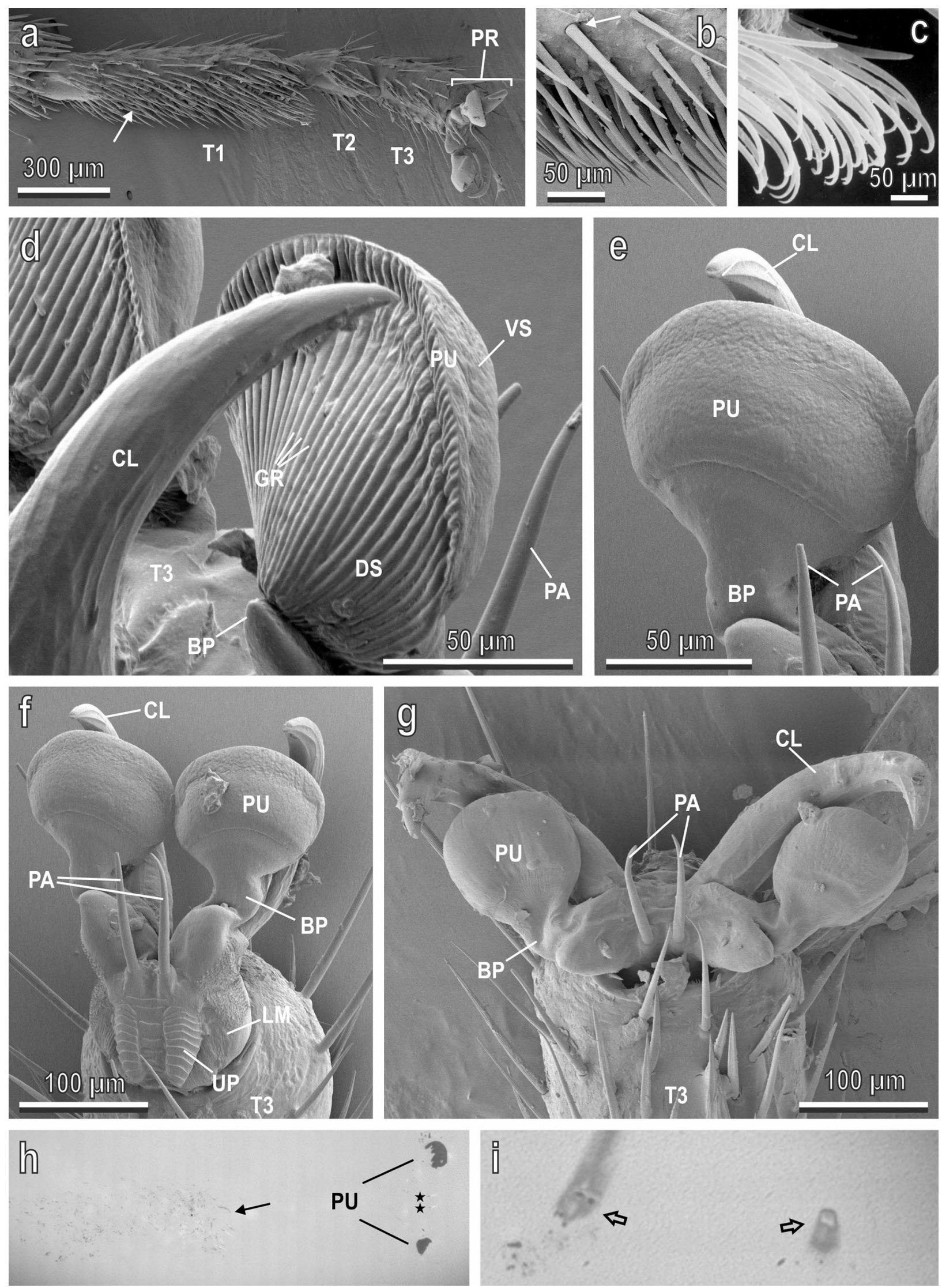
४Fig. 1 Tarsus of the adult of Coreus marginatus visualised with cryoscanning electron microscopy $(\mathbf{a}, \mathbf{b}, \mathbf{d}-\mathbf{g})$, and scanning electron microscopy (c). Foreleg contact area (h) with released fluid (i) of a living individual pulling on glass visualised with reflection contrast microscopy. a, Three tarsomere (T1-T3) and pretarsus (PR). Arrow points out the adhesive setae at the basitarsus; $\mathbf{b}$ Detail of a showing the adhesive setae with their socketed insertion (arrows) and blunt tip; c Air-dried adhesive setae with curled tip; d Dorsal view of the pretarsus showing a claw (CL) and the pulvilli (PU) with their smooth ventral surface (VS) and grooves (GR) on the dorsal surface (DS). $P A$ paraempodia, $B P$ basipulvillus, $T 3$ third tarsomere; e Ventral surface of the pulvillus (PU). Note the two paraempodia (PA) and the sclerotised basipulvillus (BP). $C L$ claw; $\mathbf{f}$ Ventral view of the pretarsus when the unguitractor tendon is relaxed and the claws (CL) and pulvilli (PU) are straight and aligned. In this condition, the unguitractor plate (UP) with its microplates surrounded by a cuticular lamina $(\mathrm{LM})$ is clearly visible. $B P$ basipulvillus, $P A$ paraempodia, $T 3$ third tarsomere; $g$ Ventral view of the pretarsus when the tendon is strained and the claws (CL) and pulvilli (PU) are bent and spread. BP basipulvillus, $P A$ paraempodia, $T 3$ third tarsomere; $\mathbf{h}$ Areas of contact with the substrate of pulvilli (PU), adhesive setae (arrow) and paraempodia (asterisk); i Traces of released fluid (arrows) from pulvilli on the substrate

the tendon is strained, the claws and pulvilli are bent and laterally spread (Fig. 1f, g).

As revealed by reflection contrast microscopy, during walking on a smooth surface, $C$. marginatus feet contact the substrate using mainly the ventral surfaces of the distal portions of the pulvilli, the setae of the hairy adhesive pad and the paraempodia (Fig. 1h). After detaching the leg from the surface, a consistent amount of fluid remains on the substrate, mostly in correspondence to pulvilli, especially after pulling them along the substrate (Fig. 1i).

Semi-thin sections and ultra-thin sections observed under TEM reveal the internal structure of the pulvilli (Fig. 2). Pulvilli are constituted of a complex cuticle in their distal portion: a thin outermost cuticular layer (epicuticle) bordering an inner cuticular rod layer, consisting of rods oriented distally at an angle of $40^{\circ}$ to the surface plane (Fig. 2a-f). This cuticular rod layer is supported by a cuticular plate representing an internal apodeme (Fig. 2a, b, d, e). A connection is visible between the lumen of the pulvillus and the distal part of the pulvillus characterised by rods (asterisk in Fig. 2e). Microfolds are occasionally present on the ventral side of the pulvillus (Fig. 2c, e). Along the epicuticular outer layer, numerous porous channels are clearly seen in Pt/C-coated ultra-thin sections (Fig. 2g). In some images, even the opening to the outside of the pore channels is clearly visible (inset of Fig. 2g).

The dorsal side of pulvilli is characterised by a grooved surface constituted of caps and grooves (Figs. 1d, 3). The caps are constituted of thick sclerotised cuticle, while the grooves have much thinner cuticle (Fig. 3c, d).
As revealed by fluorescence light microscopy, the cuticle surrounding the unguitractor plate appears blue, thus revealing high proportion of resilin; while the plate itself and its microplates are sclerotised (Fig. 4). A sclerotised tarsal apodeme is clearly visible in connection with the pretarsal apodemes representing the two sclerotised plates sustaining the two complexes claw-pulvillus (Fig. 4, see semi-thin sections in Figs. 5, 6). All these sclerotised portions are immersed in the lamina, rich with resilin. The ventral side of the pulvilli is constituted of large proportions of resilin, whereas the basipulvilli and partly the dorsal sides of the pulvilli consist of sclerotised chitinous material (Fig. 4).

Semi-thin sections of the last tarsomere observed under the light microscope reveal the presence of a big gland occupying a wide area of the tarsus from its proximal to its distal portion (Figs. 5, 6, 7). The gland is folded on itself in its distal portion and is strictly connected to the unguitractor tendon in its proximal portion. It is constituted of a monolayer of big cells separating a wide inner compartment, the gland lumen, located ventrally, from a smaller outer compartment, the haemolymph space, located dorsally. The gland lumen is in connection with the pulvilli lumen (Fig. 5). Scolopidia are visible (Figs. 5a-c, 6a, c. Figure 9 for details of scolopidia visualised with TEM) in the outer compartment (the hemolymph space), strictly in contact with the gland cells. The gland is in close contact with two connective ligaments (Fig. 5d, e, 6b, c, g) running from the dorsal portion of the tarsus to the ventral distal tarsus, towards the two pretarsal apodemes, each sustaining the complex claw-pulvillus (Figs. 5, 6). Each ligament is attached to the ipsilateral pretarsal apodeme (Figs. 5, 6, 7).

The monolayered epithelium of the gland observed in TEM (Fig. 8) shows the presence of huge secretory cells separating the lumen of the gland from the haemolymph space (outer compartment), which is in contact with the epithelium (Fig. 8a). Each cell is characterised by an apical side extending in long microvilli bordering the gland lumen (Fig. 8a, c) and a basal membrane forming numerous long infoldings representing an extensive basal labyrinth (Fig. 8a, b). The cells have a big nucleus (Fig. 8a), numerous mitochondria (Fig. 8a-c) and well developed smooth and rough endoplasmic reticulum (Fig. 8b, d). An electron-dense flocculent material is clearly visible in the lumen of the gland in contact to the microvilli apical border (Fig. 8a, c). The cells are rich in vesicles, which accumulate especially beneath and between the microvilli (Fig. 8a, c, d). Most of the vesicles are electron translucent, but some of them are electron dense (Fig. 8c, d). Cells are strictly adhering one to the other and show desmosomes and septate junctions (Fig. 8e, f). Occasionally 

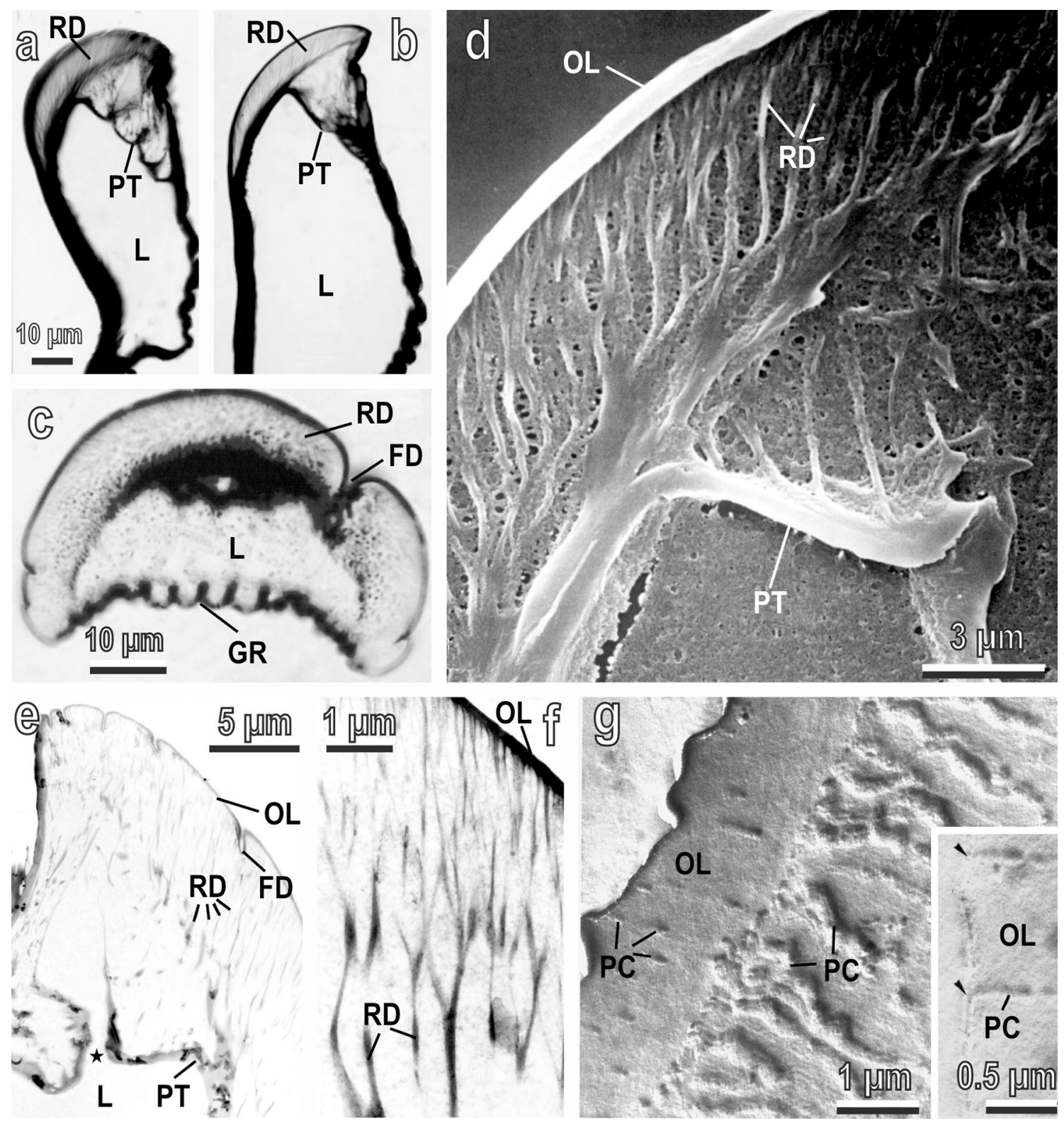

Fig. 2 Sections showing the internal structure of the pulvillus of Coreus marginatus visualised with light microscopy $(\mathbf{a}-\mathbf{c})$, scanning electron microscopy (d) and transmission electron microscopy (e-g). a-c Semi-thin sections showing the complex cuticle of the ventral side of the pulvillus. Note the rod layer (RD) supported by a cuticular plate (PT) representing an internal apodeme. $F D$ fold, $G R$ grooved dorsal surface, $L$ pulvillus lumen; d A semi-thin section treated by Maxwell solution showing the rod layer (RD) consisting of rods oriented distally at an angle of $40^{\circ}$ to the surface plane, surrounded by the outermost epicuticular layer (OL). Note that the rod layer is sup- ported by a cuticular plate (PT); e, f Ultra-thin sections revealing the fine structure of the rods (RD) terminated by the outermost epicuticular layer (OL). Note that a connection (asterisk) between the lumen of the pulvillus (L) and the distal part of the pulvillus, characterised by rods supported by the cuticular plate (PT), is visible. Folds (FD) are occasionally present along the ventral side of the pulvillus; $\mathrm{g} \mathrm{Pt} / \mathrm{C}$ coated ultra-thin section showing numerous pore channels (PC) along the epicuticular outer layer (OL). Inset shows the openings to the outside (arrow heads) of the pore channels 

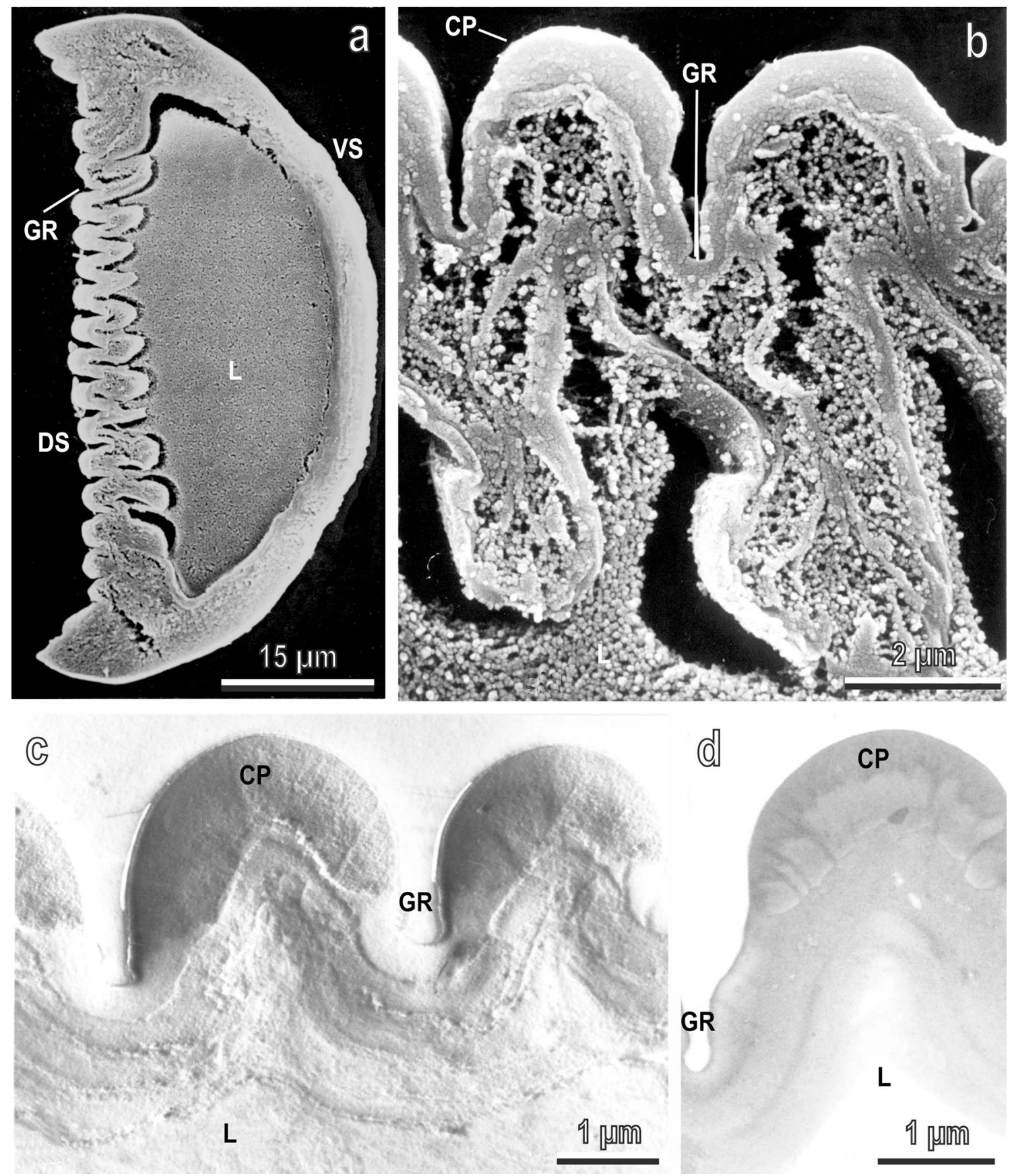

Fig. 3 Sections showing the internal structure of the pulvillus of Coreus marginatus visualised with scanning electron microscopy (a, b) and transmission electron microscopy (c, d). a Semi-thin sections treated with Maxwell solution showing the smooth ventral side (VS) and the dorsal side of pulvilli (DS) characterised by grooves (GR). L, pulvillus lumen; b Detail of a showing the caps (CP) composed by stiff cuticle and grooves (GR) composed by soft cuticle; c, d Pt/Ccoated ultra-thin section (c) and ultra-thin section (d) of the dorsal side of the pulvillus showing the caps (CP) constituted of thick rigid cuticle and the grooves (GR) having thinner softer cuticle. $L$ pulvillus lumen 

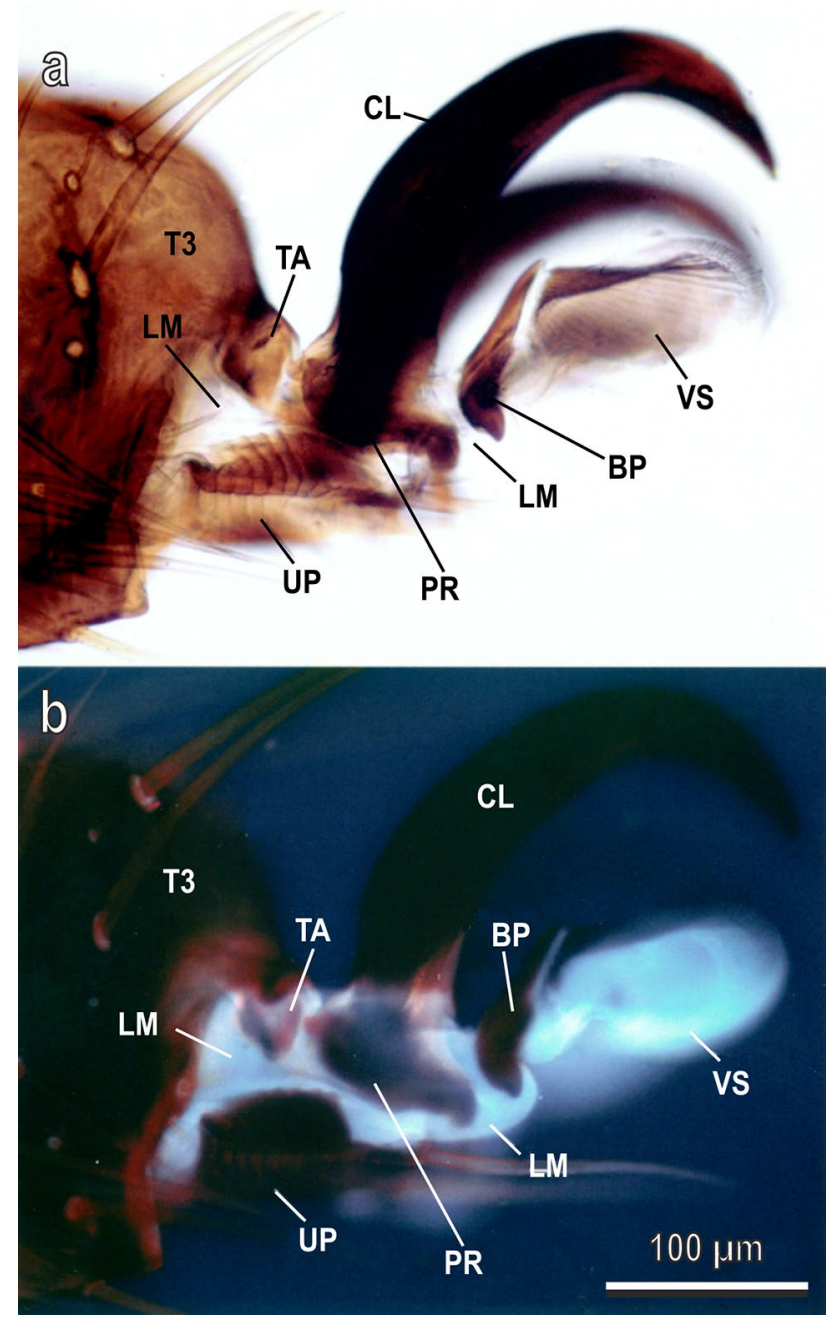

Fig. 4 Pretarsus of Coreus marginatus under the bright-field light microscope (a) and the fluorescence light microscope (b). Note that the unguitractor plate (UP), the claws (CL), the pretarsal apodeme (PR), the tarsal apodeme (TA), the basipulvilli (BP) and the dorsal portion of the pulvilli are sclerotised, while the lamina (LM) located below and around the unguitractor plate and the ventral side of the pulvilli (VS) contain high proportion of resilin. T3 third tarsomere

glycogen granules are visible in the cells (Fig. 8g). The gland in its proximal portion envelopes the unguitractor tendon, which is strictly in contact with the gland cells (Fig. 8h). Ultra-thin sections observed in TEM reveal the presence of three mononematic (= subintegumental scolopidia without any direct relationship to the cuticle) scolopidia, longitudinally oriented inside the tarsus. They are located in the haemolymph space strictly adhering to the gland cells (Fig. 9a-g). One of them is heterodynal (=innervated by two neurons), while the others are monodynal (= innervated by one neuron) (Fig. 9g). The dendritic outer segments show the typical modified cilium with a $9 \times 2+0$ arrangement of microtubules in the axoneme (Fig. 9e and inset). A scolopale cell surrounds the cilium and produces a dense cylindrical sleeve of scolopale rods around the cilia (Fig. 9e, g). The distal end of the cilium inserts into an extracellular cap, which is firmly connected to an attachment cell containing numerous longitudinally oriented microtubules (Fig. 9f). Cross sections at the level of the proximal portion of the claws reveal the presence of cells surrounding an electron-dense matrix (Fig. 9h). The cells are vacuolated (Fig. 9h), but they show morphological features very different from those present in the tarsal gland.

\section{Discussion}

The present study describes in detail the morphology of the attachment devices and of the tarsal gland in the bug Coreus marginatus, thus allowing us to trace hypothesis about the mechanism of insect attachment devices functioning, adhesive fluid production, the control of its transport and its release to the outside.

\section{The pulvilli of Coreus marginatus}

Smooth pulvilli and basitarsal hairs, together with claws, represent the tarsal attachment devices of the coreid bug $C$. marginatus. Traction force experiments on the pentatomid bug $N$. viridula (whose attachment devices are similar to $C$. marginatus) with ablated pulvilli, shaved hairs and cut-off claws (Salerno et al. 2018) revealed a great involvement of pulvilli in insect attachment on horizontal smooth and rough surfaces; while, the hairy pad, with its resilin-bearing flexible tips as previously shown for $N$. viridula (Rebora et al. 2018), seems to be important in attachment to horizontal hydrophobic substrates under water (Salerno et al. 2018) and on vertical smooth roads as well (Voigt et al. 2019).

The pulvilli of the bug C. marginatus are typical smooth attachment pads, whose ventral side shows a complex cuticle structure with a thin outermost cuticular layer (epicuticle) bordering an inner cuticular rod layer (sustained by a cuticular plate) consisting of rods oriented distally at an angle of $40^{\circ}$ to the surface plane. Such a specialised type of cuticle has evolved several times independently in arthropods (Beutel and Gorb 2001) and has been described in different insects species both with smooth attachment pads (pulvilli, euplantulae, arolium) such as the bug N. viridula (Hemiptera) (Rebora et al. 2018), cockroaches (Blattodea) 

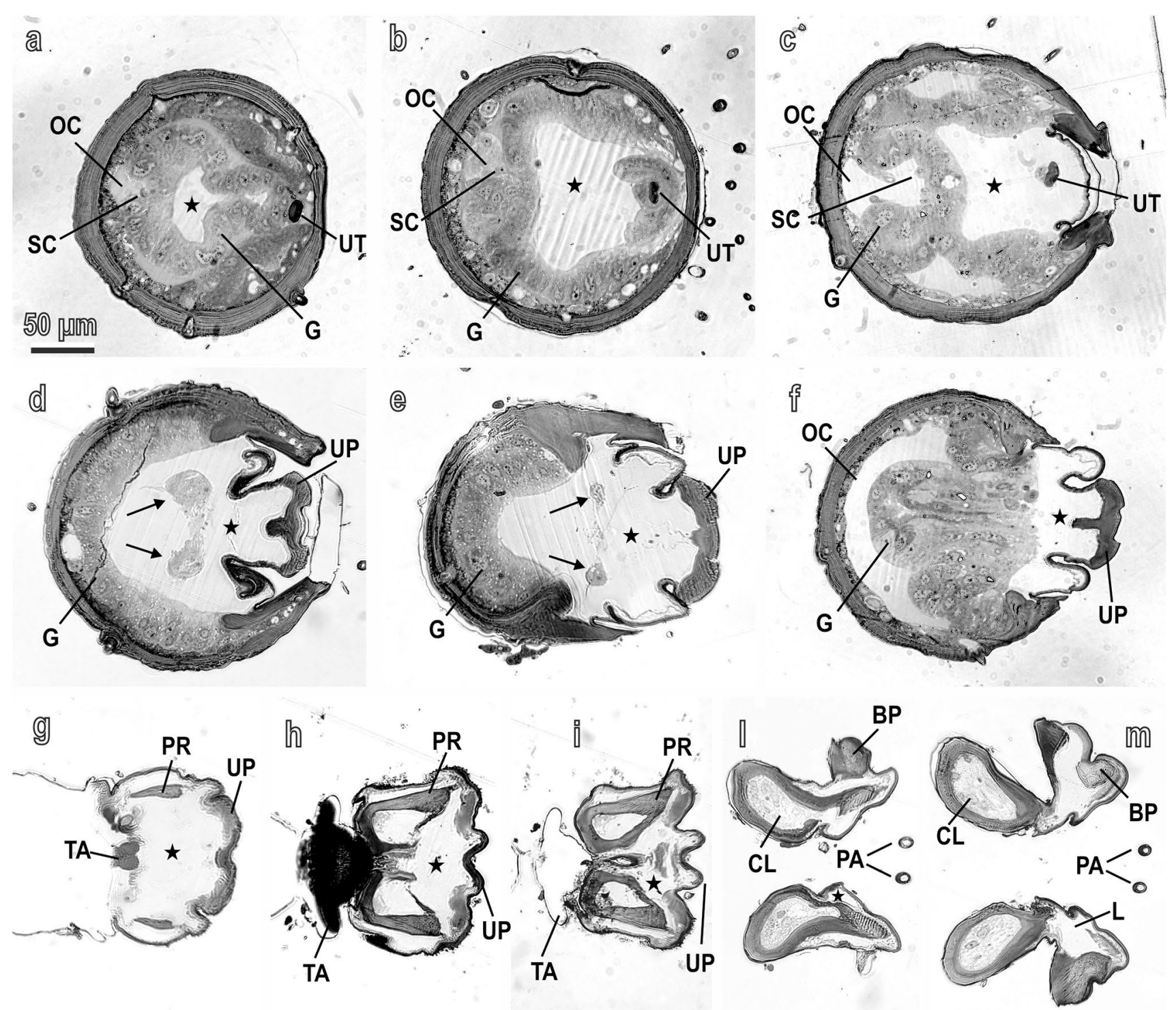

Fig. 5 Semi-thin cross sections of the last tarsomere (a-f) and of the pretarsus ( $\mathbf{g}-\mathbf{m})$ of Coreus marginatus, from the more proximal (a) to the more distal $(\mathbf{m})$ area observed in bright-field light microscope. Note the tarsal gland $(\mathrm{G})$, separating an outer compartment (OC) and an inner compartment representing the gland lumen (asterisk), in connection with the pulvilli lumen $(\mathrm{L})$. The gland in its proximal portion is strictly connected to the unguitractor tendon (UT) merging with the unguitractor plate (UP). Scolopidia (SC) are present in the outer compartment, strictly in contact with the gland cells. Note the two connective ligaments (arrows) running from the dorsal portion of the tarsus towards the two pretarsal apodemes (PR). Each pretarsal apodeme, in close contact with the tarsal apodeme (TA), sustains the complex claw-pulvillus (CL-BP). $P A$ paraempodia
(Roth and Willis 1952; Clemente and Federle 2008; Schmitt and Betz 2017), the stick insect Carausius morosus Sinéty (Phasmatodea) (Scholz et al. 2008), the grasshopper Tettigonia viridissima (L.) (Slifer 1950; Henning 1974; Gorb et al. 2000), the locusts Schistocerca gregaria (Forskål) (Kendall 1970) and Locusta migratoria (L.) (Orthoptera) (Perez Goodwyn et al. 2006), Karoophasma biedouwense
Klass (Mantophasmatodea) (Eberhard et al. 2009) and the honeybee (Hymenoptera) (Federle et al. 2001) and with hairy attachment pads, such as the fly Ceratitis capitata (Diptera) (Salerno et al. 2020) and the beetles Philonthus marginatus (Müller) (Betz and Mumm 2001) and Gastrophysa viridula (De Geer) (Coleoptera) (Eimüller et al. 2008). The specialised cuticle on the ventral side of adhesive pads 

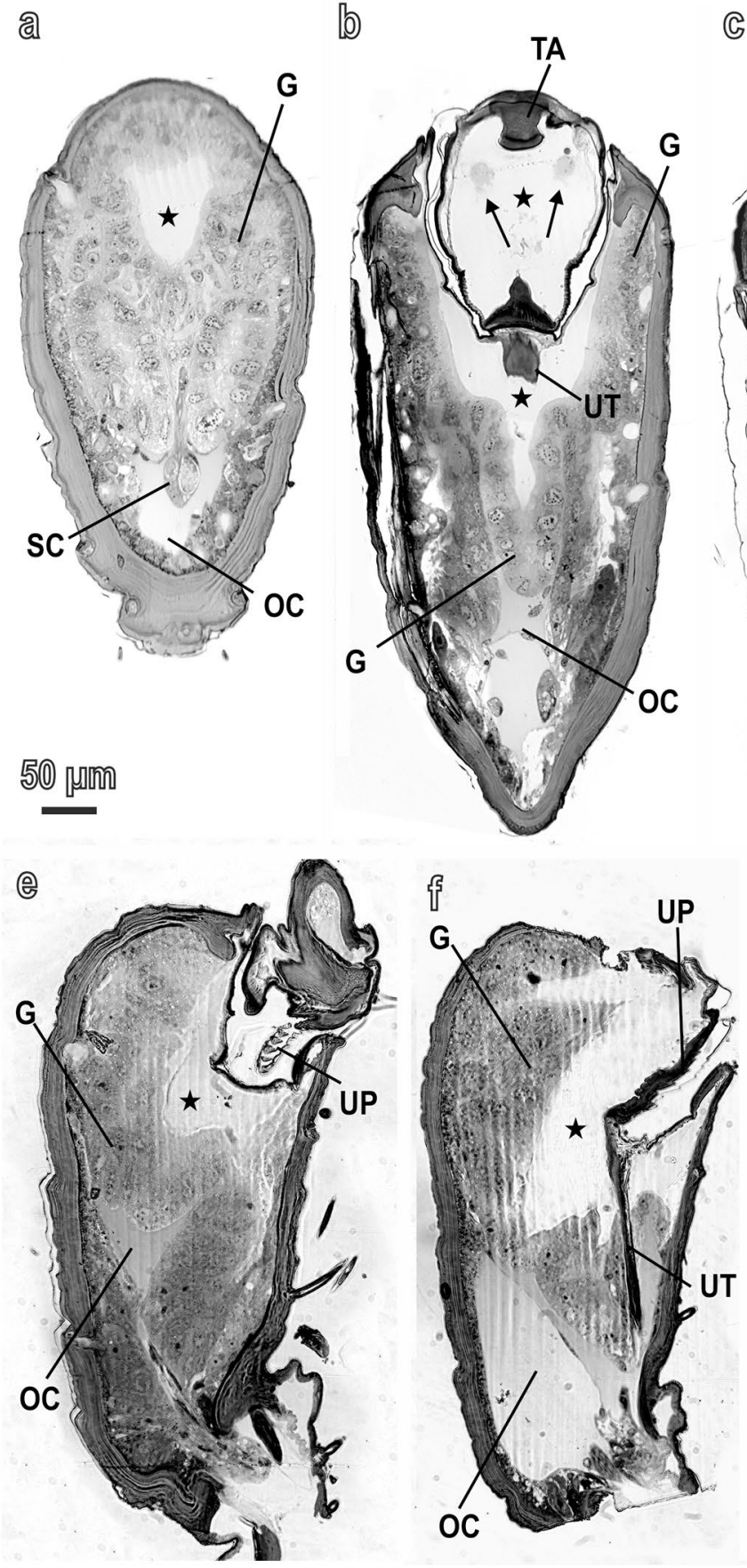

Fig. 6 Semi-thin frontal (a-d) and longitudinal (e-g) sections of the last tarsomere and of the pretarsus of Coreus marginatus, from the dorsal (a) to the ventral (d) region and from the lateral (e) to the median (g) region, observed with light microscopy. Note the tarsal gland $(\mathrm{G})$ separating an outer compartment (OC), the haemolymph space, and an inner compartment, the gland lumen (asterisk). Scolopidia (SC) are present in the outer compartment, strictly in contact
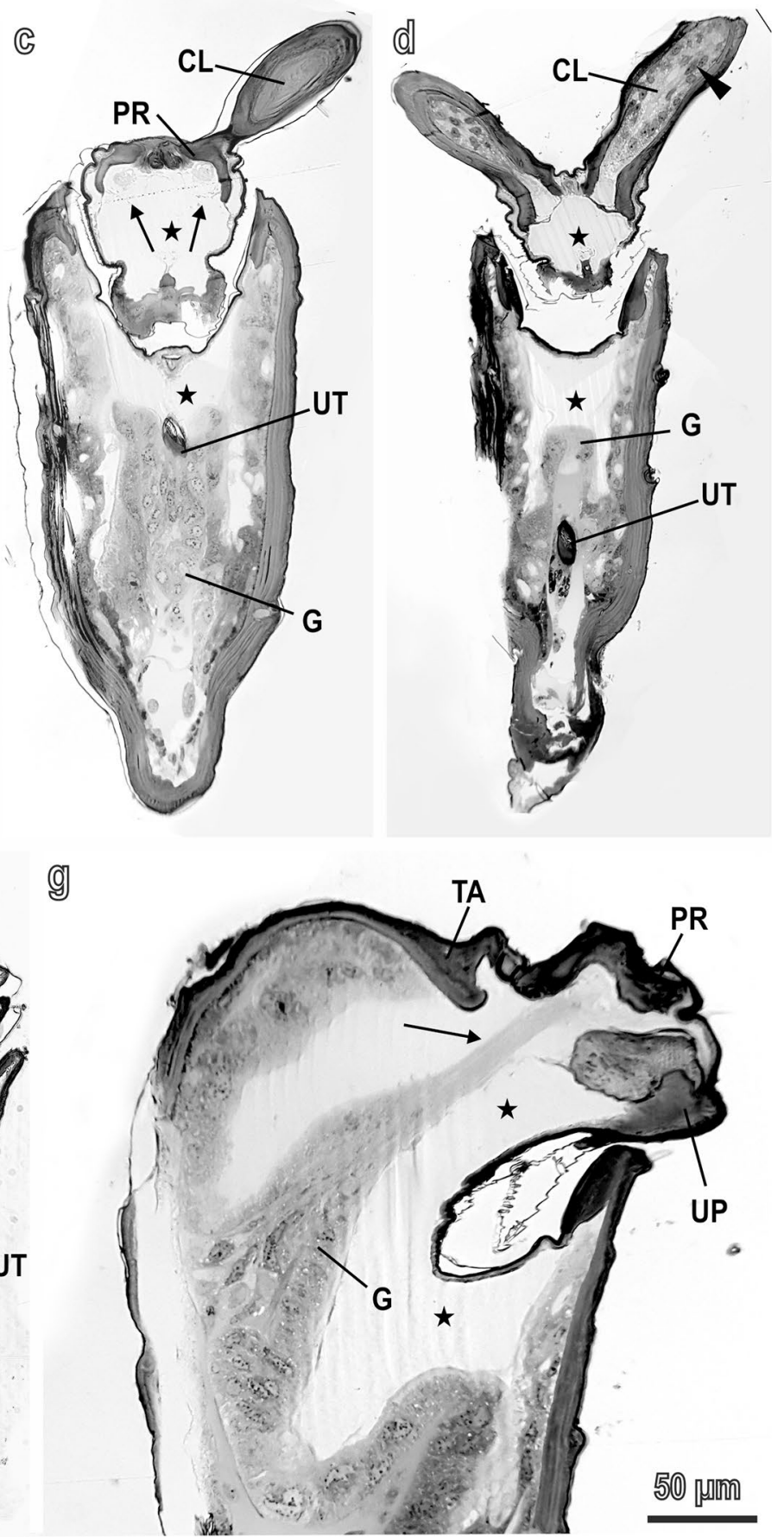

with the gland. Two connective ligaments (arrows) run from the dorsal portion of the tarsus to the ventral distal tarsus, towards the two pretarsal apodemes (PR), in close contact with the tarsal apodeme (TA). Arrow head points out to the cells inside the proximal portion of the claws (CL). UT unguitractor tendon of the musculus retractor unguis, UP unguitractor plate 


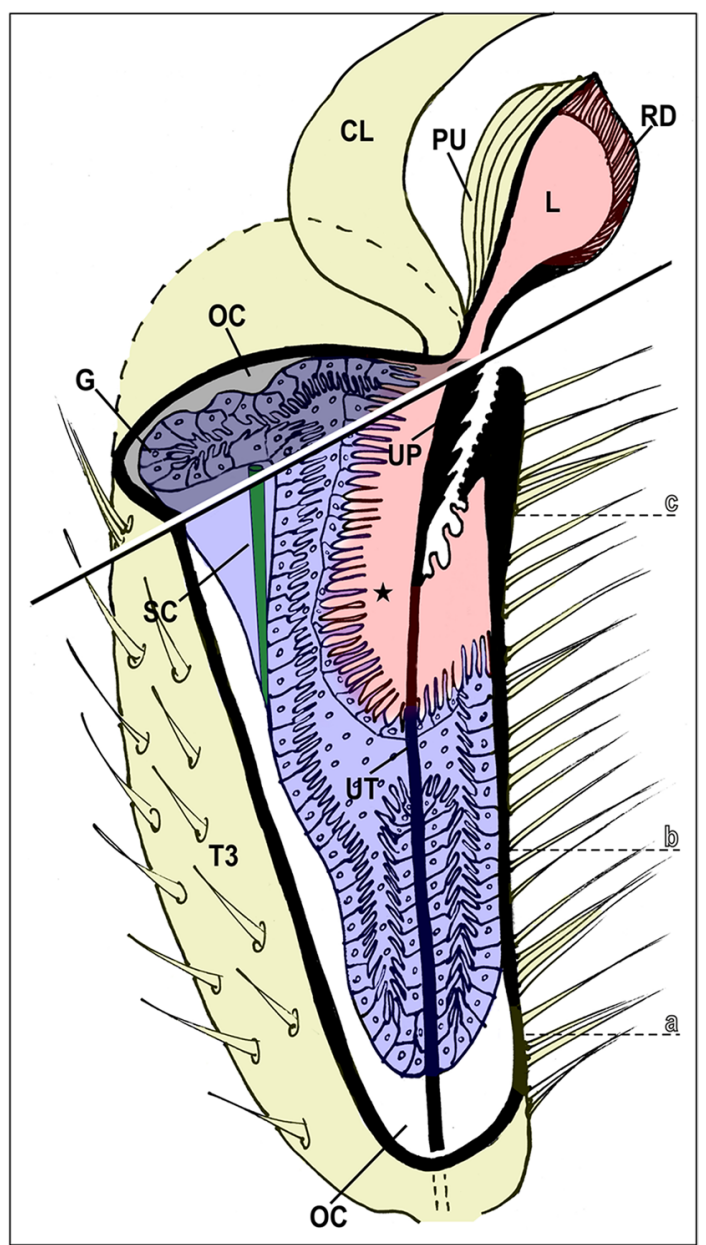

Fig. 7 Schematic reconstruction of the tarsal gland of Coreus marginatus. The third tarsomere is cut longitudinally and transversally. $C L$ claws, $G$ gland, $L$ pulvillus lumen, $O C$ outer compartment (haemolymph), $P U$ pulvillus, $R D$ rods, $S C$ scolopidia, $U P$ unguitractor plate, $U T$ unguitractor tendon, asterisk points out the inner compartment. Note the gland lumen in connection with the pulvillus lumen. a-c refer to the correspondent cross sections shown in Fig. 5

could have different functions. (1) The fibrils help the pads to adapt to surface roughness at different length scales (Gorb et al. 2000). (2) The sponge-like cuticle is the reservoir able to store the adhesion-mediating secretion, especially in insects with secreting epithelia located inside the adhesive pads (Dirks and Federle 2011b; Schmitt and Betz 2017). (3) The fibrils oriented at an angle to the surface could be related with the need to increase the contact area during pulling, decreasing the fibril angle and thereby helping the contact area to expand laterally and longitudinally (Gorb and Scherge 2000; Dirks et al. 2012).

The grooved dorsal surface of $C$. marginatus pulvilli with alternating caps having thick cuticle and grooves having thinner cuticle could be coherent with a folding mechanism leading to a strong enhancement of the contact area (Fig. 10). The volume inside the pulvillus remains the same, but the shape of the pulvillus becomes more flattened concomitantly with the unfolding of the dorsal folds. This is a hypothetical functional model that needs to be experimentally verified in further investigations. The sclerotised portions of the cuticle in the dorsal sides of pulvilli could also function as a kind of lightweight microskeleton (Vincent and Wegst 2004) protecting the vulnerable inner structures.

Pores on the cuticle of the ventral surface of heteropteran pulvilli have never been clearly observed. For this reason, a pore canal system along the ventral side of the pulvillus specialised for the transport of epidermal secretions to the cuticle surface was hypothesised (Bauchhenss 1979; Schwarz and Gorb 2003; Dirks and Federle 2011b). In $C$. marginatus, numerous pore channels are clearly visible penetrating the outer cuticular layer of the ventral side of pulvilli, thus, allowing the fluid to be transported from the pad lumen to the outside. In this regard, the transport system suggested in Heteroptera by Ghazy-Bayat and Hasenfuss (1980) for Heteroptera, seems less plausible. Specifically, they postulated that dorsal pulvillus grooves transported an adhesive fluid to the ventral pulvillus surface from the more proximal part of the leg. No clear pores have been shown on any other part of the tarsus/pretarsus and the dorsal corrugations likely serve as part of folding mechanism, as we suggested.

\section{The tarsal gland, the production of adhesive fluid and the fluid storage control}

The present ultrastructural investigation identified in $C$. marginatus a well developed gland located inside the last tarsomere. Such a gland lacking a duct can be considered a class 1 epidermal gland according to Noirot and Quennedey (1974) classification. It is composed of a monolayer of big cells bordered by very long microvilli facing the gland lumen, which is located in the ventral portion of the tarsus. All the morphological features of the cells (long infoldings of the basal region of the plasma membrane facilitating the transport of precursors of the secretion from the adjoining hemolymph toward the cytoplasm, high number of mitochondria, developed rough and smooth endoplasmic reticulum, large nucleus, glycogen) are coherent with a role of cells in active secretion and transport of fluids and ions and are similar to those present in the adhesive fluid secreting cells of other insects (see review in Betz 2010; Schmitt and Betz 2017). The cytoplasm of the tarsal gland cells in $C$. marginatus is filled with vesicles of different size and contrast: some of them are brighter, some are darker. Two types of vesicles, electron lucent and electron dense, have been described 

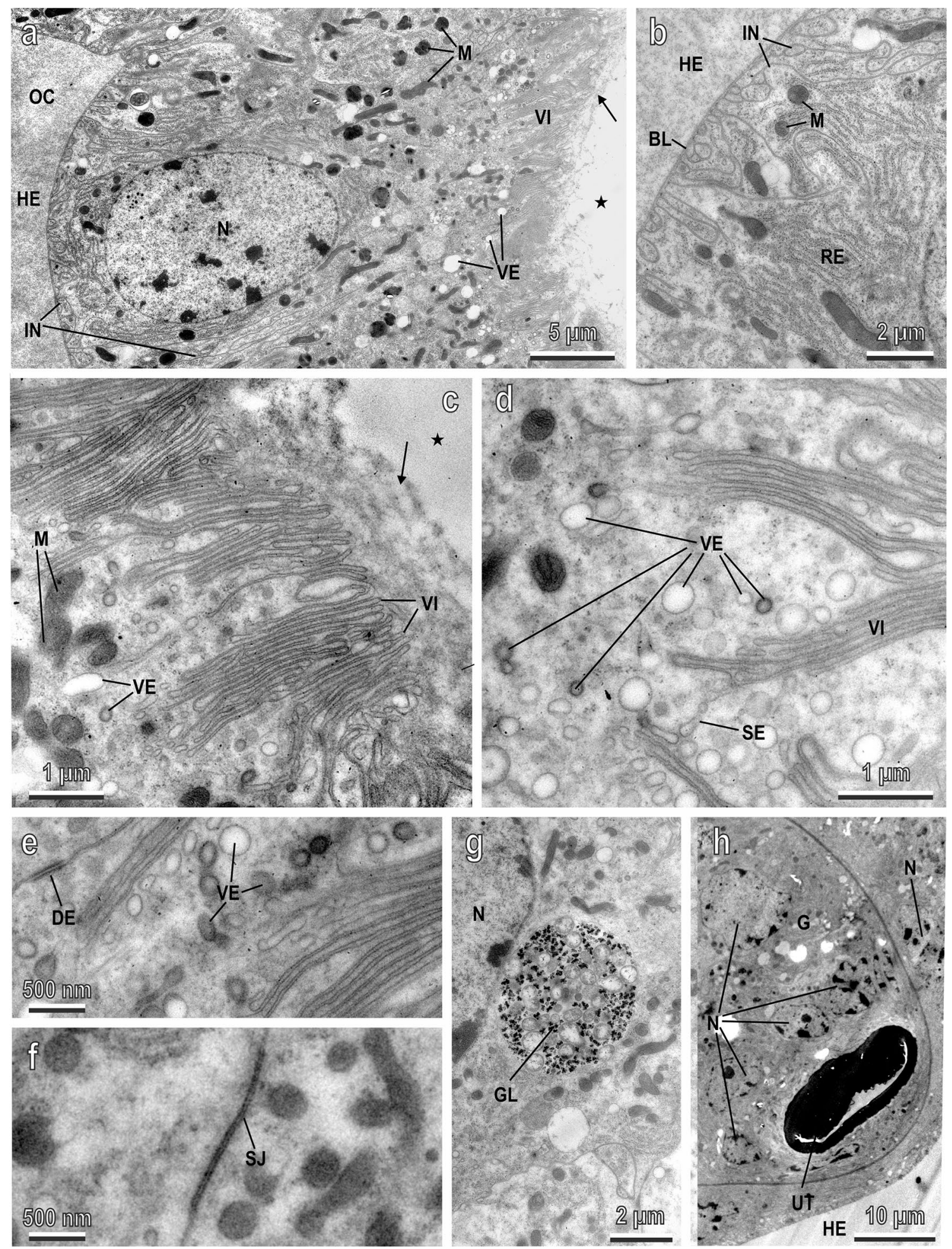
4Fig. 8 Tarsal gland of Coreus marginatus visualised with transmission electron microscopy. a Cross section of the monolayer of big secretory cells separating the lumen of the gland (asterisk) from the outer compartment (OC) with haemolymph (HE). Note the big nucleus $(\mathrm{N})$, the basal membrane forming numerous long infoldings (basal labyrinth) (IN), the apical long microvilli (VI), the high amount of mitochondria (M) and the vesicles (VE). Arrow points out to the fluid inside the gland lumen; $\mathbf{b}$ Detail of a showing the gland cell infoldings (IN) and the basal lamina (BL) in contact with the hemolymph (HE). $M$ mitochondria, $R E$ rough endoplasmic reticulum; c Detail of a showing the very long microvilli (VI) in direct contact with the fluid (arrow) inside the gland lumen (asterisk). $M$ mitochondria, $V E$ vesicles; $\mathbf{d}$ Detail of the gland cell cytoplasm showing the huge amount of vesicles (VE) of different contrast (electron translucent/electron dense) accumulated beneath and between the microvilli (VI). Note the development of the smooth endoplasmic reticulum (SE); e, f Gland cells strictly adhering one to the other showing desmosomes (DE) and septate junctions (SJ) along their lateral membrane. VE vesicles; $g$ Detail of the gland cell cytoplasm showing glycogen granules (GL). $N$ nucleus; h Detail of the gland (G) in its proximal portion showing its attachment to the unguitractor tendon (UT). $N$ nuclei of the gland cells. $H E$ hemolymph

also in the epidermal cells with secretory activity in the attachment pads of other insects, such as flies, aphids, Mantophasmatodea, cockroaches and beetles (Bauchhenss and Renner 1977; Bauchhenss 1979; Lees and Hardie 1988; Betz and Mumm 2001; Betz 2003; Eberhard et al. 2009; Schmitt and Betz 2017), thus suggesting a biphasic chemical nature of the adhesive fluid. Such a biphasic chemistry is in agreement with the emulsion described by Vötsch et al. (2002) and Dirks et al. (2010) and is composed of both hydrophobic and hydrophilic compounds (Vötsch et al. 2002; Peisker and Gorb 2012; Peisker et al. 2014; Reitz et al. 2015; Gerhardt et al. 2016; Betz et al. 2016).

Owing to the above-reported reasons, we consider the tarsal gland of $C$. marginatus as the best candidate to the adhesive fluid production. This, also in consideration that in C. marginatus, such as in other Hemiptera as $N$. viridula (Rebora et al. 2018) the pulvillus cuticle has no epidermis or secretory epithelium underneath. A secreting epithelium in the adhesive pad is present in cockroaches (Betz et al. 2017), grasshoppers (Slifer 1950) and Mantophasmatodea (Eberhard et al. 2009) or at the base of the adhesive seta in beetles (Betz 2003), but the situation is different in the pulvilli of Hemiptera (Rebora et al. 2018, present investigation) and also in Hymenoptera where arolia lack an epidermis and other structures (Federle et al. 2001; Jarau et al. 2005).

The cells located in the proximal portion of the claws of $C$. marginatus, notwithstanding the presence of white vesicles, have morphological features different from those typically reported for the adhesive fluid secreting cells of other insects (see above-reported references). The claw cells could have another function, not necessarily associated with the adhesive fluid production. Further ultrastructural investigations on Hemiptera claws could help in clarifying the role of these cells.

The vesicles from the cells of the tarsal gland reach the gland lumen (the gland reservoir), which represents a close compartment separated from the hemolymph and is in contact with the pulvillus lumen, as clearly evident in $C$. marginatus. The presence of a gland reservoir connected to the pulvillus lumen is coherent with a storage volume of adhesive fluid. In the two experimental studies measuring the pad secretion flow rate in smooth pads of cockroaches and stick insects (Dirks and Federle 2011b) and in hairy pads of beetles (Iazzolino et al. 2020), the deposited volume of fluid increased with increasing pad-surface contact time and the footprint volume decreased to zero after reaching a threshold cumulative volume, thus suggesting a limited reservoir with low liquid influx. In these two cases, the secreting epithelium is close to the adhesive pad (in the arolium of cockroaches and stick insects or at the base of the adhesive seta in beetles). It would be interesting to measure the pad secretion flow rate in other insects, such as the bug C. marginatus, whose pulvilli do not have any secretory cell inside their lumen, but show a tarsal gland with a big reservoir.

Interestingly, the tarsal gland of $C$. marginatus is proximally in close contact with the unguitractor tendon, in such a way that any movement of the tendon results in a deformation of the gland shape and gland lumen. The contraction of the musculus retractor unguis leads to the unguitractor tendon pulling, which could produce a decreased volume and increased pressure within the tarsal gland (Fig. 11). Such a change in the internal pressure could induce the fluid emission to the ventral side of the pulvillus, whose lumen is in contact with the gland reservoir, through the pore channels. Indeed, Dirks and Federle (2011b) hypothesising a role of pore canals in allowing the fluid to be released in the case of the cockroach pads, demonstrated that the mechanism of fluid release is based on compression of the pad and capillary suction, but did not exclude a contribution of the internal pad pressure to secretion transport. Such a positive pressure in the adhesive pad of $C$. marginatus could be realised by the unguitractor movements. In this regard, it is worth to highlight that observations of the tarsal gland filled with fluorescein disodium salt revealed the connection between the gland lumen and pulvilli (Fig. 11c). In particular, movements of the unguitractor tendon (performed by the 


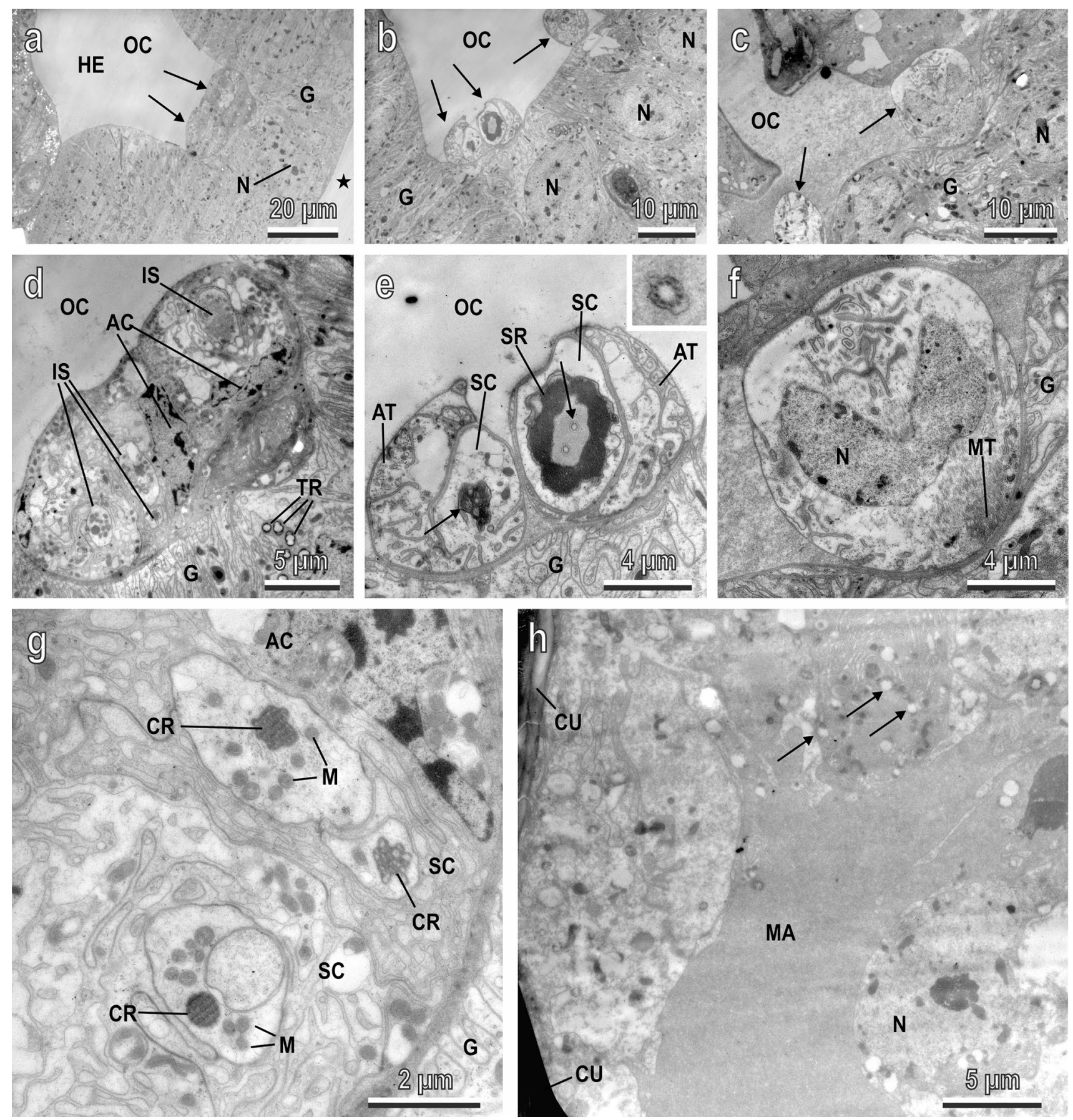

Fig. 9 Scolopidia attached to the tarsal gland $(\mathrm{a}-\mathrm{g})$ and proximal portion of the claws (h) of Coreus marginatus visualised with transmission electron microscopy. a-c Cross sections of the gland at different levels, from more proximal (a) to more distal (c) areas, showing three mononematic scolopidia (arrows) located in the outer compartment (OC) with hemolymph (HE) strictly adhering to the gland cells (G). Asterisk points out the gland lumen. $N$ nuclei of the gland cells; d Detail of a showing three scolopidia in the outer compartment (OC) at the level of the inner dendritic segments (IS) surrounded by the accessory cells (AC). $G$ gland, $T R$ trachee; e Detail of b showing two scolopidia at the level of the outer dendritic segments, each surrounded by the attachment cell (AT), which envelopes the scolopale cell (SC) producing the scolopale rods (SR). Note in the inset the typical modified cilia (arrows) with a $9 \times 2+0$ arrangement of microtubules in the axoneme. $G$ gland; $O C$ outer compartment; $\mathbf{f}$ Detail of c showing one scolopidium at the level of the attachment cell. Note the nucleus $(\mathrm{N})$ of the attachment cell and the high number of microtubules (MT) in close contact with the gland cells (G); $\mathbf{g}$ Detail of $\mathbf{d}$ showing two scolopidia at the level of the inner dendritic segments, close to the ciliary rootlets (CR) surrounded by scolopale cell (SC). $A C$ accessory cell, $G$ gland cells, $M$ mitochondria; $\mathbf{h}$ Cross sections at the level of the proximal portion of the claws showing cells surrounding an electron-dense matrix (MA). The cells are vacuolated (arrows). $C U$ cuticle, $N$ nucleus 


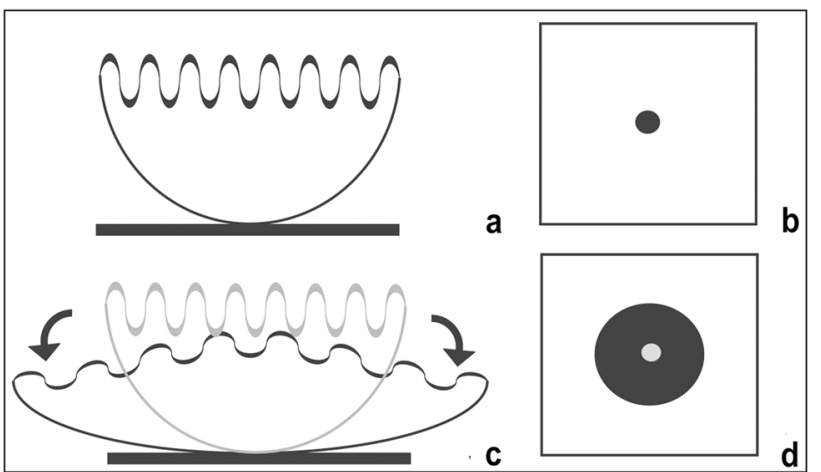

Fig. 10 Scheme of the geometry of the pulvillus of Coreus marginatus in contact. a, c Configuration of the pulvillus in cross section. $\mathbf{b}$, d Contact area projection. a, b Beginning of the contact formation with the substrate. c, $\mathbf{d}$ Contact is formed under load (arrows) applied to the pulvillus (superimposed with the grey outline, showing initial stage of contact formation, see $\mathbf{a}, \mathbf{b}$ ). The volume of the pulvillus remains the same, but the shape of the pulvillus becomes more flattened due to unfolding of dorsal folds. This action leads to the strong enlargement of the contact area

observer with forceps) allowed the fluid to spread from the gland lumen into the pulvilli.

The tarsal gland of C. marginatus is morphologically similar to the tarsal gland of Diptera (Bauchhenss 1979) and to the arolium gland of Hymenoptera (Federle et al. 2001; Jarau et al. 2005; Nijs and Billen 2015; Billen et al. 2017). Also in these cases, there is an outer and inner compartments, and the unguitractor tendon is in contact with the gland. Bauchhenss (1979) hypothesised an involvement of this gland in the adhesive fluid production, together with the gland present inside the pulvilli, and suggested the involvement of pore channels in the pulvilli adhesive setae for the fluid release. However, in Hymenoptera, the lack of any pores leading the fluid to the outside induced researchers to hypothesise that the secretion of this gland in Hymenoptera have an hydraulic function and is used only for increasing the pressure inside the arolium, thus allowing its unfolding (Federle et al. 2001; Jarau et al. 2005). A more detailed analysis of the ultrastructure of the ventral side of the arolium in Hymenoptera could clarify the possible occurrence of pore channels for the fluid emission, thus reconsidering the role of the arolium gland in producing the adhesive fluid. A role of the arolium gland in producing the adhesive fluid could be hypothesised also considering that (1) the arolium does not show any internal secretory epithelium; (2) a pressure-driven mechanism of arolium unfolding is mainly true for small representatives of Hymenoptera, while large hornets can do it mainly mechanically (Frantsevich and Gorb 2002, 2004).
The present study on the tarsus of $C$. marginatus also identified the presence of mononematic scolopidia running longitudinally in the dorsal side of the tarsus, strictly adhering to the gland. From the same area, strictly connected to the gland, two ligaments run to the ventral distal tarsus, towards the two pretarsal apodemes, each sustaining the complex claw-pulvillus. Scolopidia are mechanoreceptors sensing the internal stretching of the body parts and their presence and position in the last tarsomere of $C$. marginatus is coherent with the ability to sense the internal stretching of the tarsus during the unguitractor tendon pulling and the consequent rotation of the complex claw-pulvillus, as suggested in other insects (e.g. Wiese and Schmidt 1974; Seifert and Heinzeller 1989). In consideration of the close association of scolopidia with the gland cells, a possible role of scolopidia could be hypothesised also in sensing the stretching of the gland during the unguitractor tendon pulling to keep under control the storage volume of the gland reservoir during insect walking or pulling. This neuronal control could be useful also for limiting the further influx of fluid in the gland reservoir when the storage volume is full.

\section{Conclusions}

As reported by Schmitt and Betz (2017) "To date, only a few studies have been conducted that have comprehensively elucidated the morphology of insect tarsal adhesive organs by combining studies on (1) the secretory active tissues, (2) the cuticular structures that function in the storage, distribution, and release of the adhesion-mediating secretion, and (3) the external morphology of the adhesive organs". In this context, the present investigation on the ultrastructure of the attachment devices and the tarsal gland of the bug C. marginatus could help to better understand the mechanisms of insect adhesive fluid production, the fluid emission and control of its transport toward the exterior, especially in Hemiptera, but also in other insect groups with similar morphological features. These mechanisms indeed could be similar among different insect groups in relation with the evolutionary convergences evolved to enhance the attachment ability to the substrate (e.g. the presence of cuticular rods at the ventral surface of both hairy and smooth attachment pads), but also different (such as the adhesive fluid secretory epithelium occupying different areas of the tarsus in different insect orders). Finally, this paper detected mononematic scolopidia that can be good candidates for the sensory control of insect attachment, which to the large extent remains unknown. 
Fig. 11 Schematic reconstruction of the tarsal gland of Coreus marginatus under action of the musculus retractor unguis (a) and gland filled with fluorescein disodium salt $(\mathbf{b}, \mathbf{c})$. a (1) Resting position of pretarsus (musculus retractor unguis is relaxed). a (2), Pretarsus configuration under contracted musculus retractor unguis. When force (red arrow, F) is applied to the tendon, claws and pulvilli rotate (blue arrow, $\mathrm{R})$ ventrally, come in contact with the substrate and liquid will be delivered into contact region (green arrowheads, L) due to the decreased volume and increased pressure within the tarsal gland; b Capillary (C) with fluorescein disodium salt inserted (arrow) in the tarsal gland under stereomicroscope; c, Fluorescein disodium salt spread from the gland lumen (asterisk) into the pulvilli (PU) visualised with fluorescence light microscopy. $C L$ claws

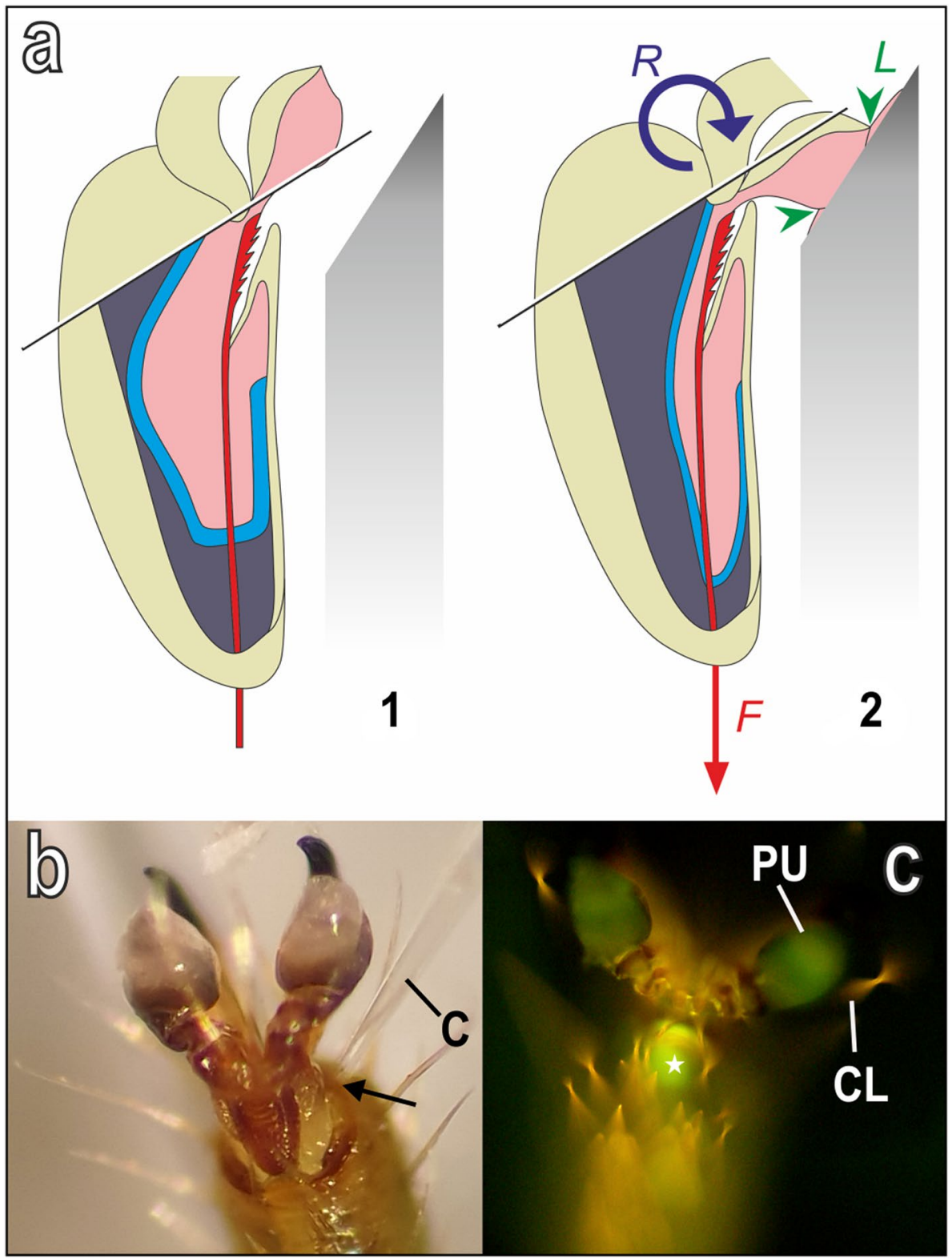

Acknowledgments The research was performed based on the knowledge acquired during an Erasmus+ grant (Staff mobility for training 2019-20 (MR, GS) at the Zoological Institute, Functional Morphology and Biomechanics, Kiel University, Kiel, Germany. This research was funded by the German Science Foundation, DFG grant GO 995/34-1. We thank the Central Microscopy Facility at the Department of Biology, Kiel University for technical support during TEM observations.

Author contributions The study was designed by all the authors. Cryoscanning electron microscopy investigations were performed by SNG. Transmission electron microscopy investigations were performed by MR and SNG. EVG and SNG performed the light and fluorescence microscopy analyses. EVG performed the scanning electron microscopy of semi-thin sections treated with Maxwell's fluid. MR, SP and SNG realised the semi-thin sections. GS performed the reflection contrast microscopy observations. GS and SP performed the fluorescein injection observations. SNG realised the schematic reconstructions. MR and GS wrote the manuscript. All authors discussed the results and participated in the final editing of the manuscript.

Funding Open Access funding provided by Università degli Studi di Perugia. The research was performed based on the knowledge acquired during an Erasmus + grant (Staff mobility for training 2019-2020 (M.R., G.S.) at the Zoological Institute, Functional Morphology and Biomechanics, Kiel University, Kiel, Germany. This research was funded by the German Science Foundation, DFG grant GO 995/34-1 (S.N.G.).

\section{Compliance with ethical standards}

Conflict of interest All authors declare that they have no conflict of interest. 
Ethical approval All applicable international, national, and institutional guidelines for the care and use of animals were followed. No endangered species or animals from protected areas were used for this study. This article does not contain any studies with human participants performed by any of the authors.

Open Access This article is licensed under a Creative Commons Attribution 4.0 International License, which permits use, sharing, adaptation, distribution and reproduction in any medium or format, as long as you give appropriate credit to the original author(s) and the source, provide a link to the Creative Commons licence, and indicate if changes were made. The images or other third party material in this article are included in the article's Creative Commons licence, unless indicated otherwise in a credit line to the material. If material is not included in the article's Creative Commons licence and your intended use is not permitted by statutory regulation or exceeds the permitted use, you will need to obtain permission directly from the copyright holder. To view a copy of this licence, visit http://creativecommons.org/licenses/by/4.0/.

\section{References}

Andersen SO, Weis-Fogh T (1964) Resilin, a rubber-like protein in arthropod cuticle. Adv Insect Physiol 2:1-65

Bauchhenss E (1979) Die Pulvillen von Calliphora erythrocephala Meig. (Diptera, Brachycera) als Adhäsionsorgane. Zoomorphologie 93:99-123

Bauchhenss E, Renner M (1977) Pulvillus of Calliphora erythrocephala Meig. (Diptera; Calliphoridae). Int J Insect Morphol Embryol $6: 225-227$

Betz O (2003) Structure of the tarsi in some Stenus species (Coleoptera, Staphylinidae): External morphology, ultrastructure, and tarsal secretion. J Morphol 255:24-43

Betz O (2010) Adhesive exocrine glands in insects: morphology, ultrastructure, and adhesive secretion. In: von Byern J, Grunwald I (eds) Biological adhesive systems. Springer, Vienna, pp 111-152

Betz O, Mumm R (2001) The predatory legs of Philonthus marginatus (Coleoptera, Staphylinidae): functional morphology and tarsal ultrastructure. Arthropod Struct Dev 30:77-97

Betz O, Maurer A, Verheyden AN, Schmitt C, Kowalik T, Braun J, Grunwald I, Hartwig A, Neuenfeldt M (2016) First protein and peptide characterization of the tarsal adhesive secretions in the desert locust, Schistocerca gregaria, and the Madagascar hissing cockroach, Gromphadorhina portentosa. Insect Mol Biol 25:541-549

Betz O, Frenzel M, Steiner M, Vogt M, Kleemeier M, Hartwig M, Sampalla B, Rupp F, Boley M, Schmitt C (2017) Adhesion and friction of the smooth attachment system of the cockroach Gromphadorhina portentosa and the influence of the application of fluid adhesives. Biol Open 6:589-601

Beutel RG, Gorb SN (2001) Ultrastructure of attachment specializations of hexapods (Arthropoda): evolutionary patterns inferred from a revised ordinal phylogeny. J Zool Syst Evol Res 39:177-207

Billen J, Al-Khalifa MS, Silva RR (2017) Pretarsus structure in relation to climbing ability in the ants Brachyponera sennaarensis and Daceton armigerum. Saudi J Biol Sci 24:830-836

Clemente CJ, Federle W (2008) Pushing versus pulling: division of labour between tarsal attachment pads in cockroaches. Proc R Soc B-Biol Sci 275:1329-1336

Clemente CJ, Bullock JMR, Beale A, Federle W (2010) Evidence for self-cleaning in fluid-based smooth and hairy adhesive systems of insects. J Exp Biol 213:635-642
Dirks JH, Federle W (2011a) Fluid-based adhesion in insects-principles and challenges. Soft Matter 7:11047

Dirks JH, Federle W (2011b) Mechanisms of fluid production in smooth adhesive pads of insects. J R Soc Interface 8:952-960

Dirks JH, Clemente CJ, Federle W (2010) Insect tricks: two-phasic foot pad secretion prevents slipping. J R Soc Interface 7:587-593

Dirks JH, Li M, Kabla A, Federle W (2012) In vivo dynamics of the internal fibrous structure in smooth adhesive pads of insects. Acta Biomater 8:2730-2736

Dixon AFG, Croghan PC, Gowing RP (1990) The mechanism by which aphids adhere to smooth surfaces. J Exp Biol 152:243-253

Eberhard MJB, Pass G, Picker MD, Beutel R, Predel R, Gorb SN (2009) Structure and function of the arolium of Mantophasmatodea (Insecta). J Morph 270:1247-1261

Edwards JS, Tarkanian M (1970) The adhesive pads of Heteroptera: a reexamination. Physiol Entomol 45:1-5

Eimüller T, Guttmann P, Gorb SN (2008) Terminal contact elements of insect attachment devices studied by transmission X-ray microscopy. J Exp Biol 211:1958-1963

Federle W, Brainerd EL, McMahon TA, Hölldobler B (2001) Biomechanics of the movable pretarsal adhesive organ in ants and bees. Proc Natl Acad Sci USA 98:6215-6220

Federle W, Riehle M, Curtis AS, Full RJ (2002) An integrative study of insect adhesion: mechanics and wet adhesion of pretarsal pads in ants. Integr Comp Biol 42:1100-1106

Frantsevich L, Gorb SN (2002) Arcus as a tensegrity structure in the arolium of wasps (Hymenoptera: Vespidae). Zoology 105:225-237

Frantsevich L, Gorb SN (2004) Structure and mechanics of the tarsal chain in the hornet, Vespa crabro (Hymenoptera: Vespidae): implications on the attachment mechanism. Arthropod Struct Dev 33:77-89

Gerhardt H, Betz O, Albert K, Lämmerhofer M (2016) Insect adhesion secretions: similarities and dissimilarities in hydrocarbon profiles of tarsi and corresponding Tibiae. J Chem Ecol 42:725-738

Ghazi-Bayat A (1979) Zur Oberflächenstruktur der tarsalen Haftlappen von Coreus marginatus (L.) (Coreidae, Heteroptera). Zool Anz 203:345-347

Ghazi-Bayat A, Hasenfuss I (1980) Zur Herkunft der Adhäsionsflüssigkeit der tarsalen Haftlappen bei den Pentatomidae (Heteroptera). Zool Anz 204:13-18

Gorb SN (1999) Serial elastic elements in the damselfly wing: mobile vein joints contain resilin. Naturwissenschaften 86:552-555

Gorb SN, Gorb EV (2004) Ontogenesis of the attachment ability in the bug Coreus marginatus (Heteroptera, Insecta). J Exp Biol 207:2917-2924

Gorb EV, Gorb SN (2009) Functional surfaces in the pitcher of the carnivorous plant Nepenthes alata: a cryo-SEM approach. In: Gorb S (ed) Functional surfaces in biology_adhesion related phenomena, vol 2. Springer, Dordrecht, pp 205-238

Gorb SN, Scherge M (2000) Biological microtribology: anisotropy in frictional forces of orthopteran attachment pads reflects the ultrastructure of a highly deformable material. Proc R Soc Lond B 267:1239-1244

Gorb SN, Jiao Y, Scherge M (2000) Ultrastructural architecture and mechanical properties of attachment pads in Tettigonia viridissima (Orthoptera Tettigoniidae). J Comp Physiol A 186:821-831

Heepe L, Kovalev AE, Gorb SN (2014) Direct observation of microcavitation in underwater adhesion of mushroom-shaped adhesive microstructure. Beilstein J Nanotech 5:903-909

Henning B (1974) Morphologie und Histologie der Tarsen von Tettigona viridissima. Z Morphol Tiere 79:323-342

Hrušková M, Honìk A, Pekár S (2005) Coreus marginatus (Heteroptera: Coreidae) as a natural enemy of Rumex obtusifolius (Polygonaceae). Acta Oecol 28:281-287 
Iazzolino A, Cerkvenik U, Tourtit Y, Ladang A, Compère P, Gilet $\mathrm{T}$ (2020) Liquid dispensing in the adhesive hairy pads of dock beetles. J R Soc Interface 17:20200024

Jarau S, Hrncir M, Zucchi R, Barth FG (2005) Morphology and structure of the tarsal glands of the stingless bee Melipona seminigra. Naturwissenschaften 92:147-150

Kendall MD (1970) The anatomy of tarsi of Schistocerca gregaria Forskal. Z Zellforsch Mik Ana 109:112-137

Lees AM, Hardie J (1988) The organs of adhesion in the aphid Megoura viciae. J Exp Biol 136:209-228

Maxwell MH (1978) Two rapid and simple methods used for the removal of resins from $1.0 \mathrm{~mm}$ thick epoxy sections. J Microsc 112:253-255

Michels J, Gorb SN (2012) Detailed three-dimensional visualization of resilin in the exoskeleton of arthropods using confocal laser scanning microscopy. J Microsc 245:1-16

Michels J, Appel E, Gorb SN (2016) Functional diversity of resilin in Arthropoda. Beilstein J Nanotech 7:1241-1259

Nijs C, Billen J (2015) Exocrine glands in the legs of the social wasp Vespula vulgaris. Arthropod Struct Dev 44:433-443

Noirot CH, Quennedey A (1974) Fine structure of insect epidermal glands. Annu Rev Entomol 19:61-80

Peisker H, Gorb SN (2012) Evaporation dynamics of tarsal liquid footprints in flies (Calliphora vicina) and beetles (Coccinella septempunctata). J Exp Biol 215:1266-1271

Peisker H, Michels J, Gorb SN (2013) Evidence for a material gradient in the adhesive tarsal setae of the ladybird beetle Coccinella septempunctata. Nat Commun 4:1661

Peisker H, Heepe L, Kovalev A, Gorb SN (2014) Comparative study of the fluid viscosity in tarsal hairy attachment systems of flies and beetles. J R Soc Interface 11:1-7

Perez Goodwyn P, Peressadko A, Schwarz H, Kastner V, Gorb S (2006) Material structure, stiffness, and adhesion: why attachment pads of the grasshopper (Tettigonia viridissima) adhere more strongly than those of the locust (Locusta migratoria) (Insecta: Orthoptera). J Comp Physiol A 192:1233-1243

Ploem JS (1975) Reflection-contrast microscopy as a tool for investigation of the attachment of living cells to a glass surface. In: van Furth R (ed) Mononuclear phagocytes in immunity, infection and pathology. Blackwell, Oxford, pp 405-421

Rebora M, Michels J, Salerno G, Heepe L, Gorb E, Gorb S (2018) Tarsal attachment devices of the southern green stink bug Nezara viridula (Heteroptera: Pentatomidae). J Morphol 279:660-672

Reitz M, Gerhardt H, Schmitt C, Betz O, Albert K, Lammerhofer M (2015) Analysis of chemical profiles of insect adhesion secretions by gas chromatography-mass spectrometry. Anal Chim Acta 854:47-60

Roth LM, Willis ER (1952) Tarsal structure and climbing ability of cockroaches. J Exp Biol 119:483-517
Salerno G, Rebora M, Gorb E, Kovalev A, Gorb S (2017) Attachment ability of the southern green stink bug Nezara viridula (Heteroptera: Pentatomidae). J Comp Physiol A 203:1-11

Salerno G, Rebora M, Kovalev A, Gorb E, Gorb S (2018) Contribution of different tarsal attachment devices to the overall attachment ability of the stink bug Nezara viridula. J Comp Physiol A 204:627-438

Salerno G, Rebora M, Piersanti S, Gorb E, Gorb S (2020) Mechanical ecology of fruit-insect interaction in the adult Mediterranean fruit fly Ceratitis capitata (Diptera: Tephritidae). Zoology 139:125748

Schmitt C, Betz O (2017) Morphology and ultrastructure of the tarsal adhesive organs of the Madagascar hissing cockroach Gromphadorhina portentosa. Cell Tissue Res 370:243-265

Scholz I, Baumgartner W, Federle W (2008) Micromechanics of smooth adhesive organs in stick insects: pads are mechanically anisotropic and softer towards the adhesive surface. J Comp Physiol A 194(4):373-384

Schwarz H, Gorb S (2003) Method of platinum-carbon coating of ultrathin sections for transmission and scanning electron microscopy: an application for study of biological composites. Microsc Res Tech 62(3):218-224

Seifert P, Heinzeller T (1989) Mechanical, sensory and glandular structures in the tarsal unguitractor apparatus of Chironomus riparius (Diptera, Chironomidae). Zoomorphology 109:71-78

Slifer E (1950) Vulnerable areas on the surface of the tarsus and pretarsus of the grasshopper (Acrididae, Orthoptera); with special reference to the arolium. Ann Entomol Soc Am 43:173-188

Vincent JFV, Wegst UGK (2004) Design and mechanical properties of insect cuticle. Arthropod Struct Dev 33(3):187-199

Voigt D, Gorb E, Gorb S (2007) Plant surface-bug interactions: Dicyphus errans stalking along trichomes. Arthropod Plant Interact 1(4):221-243

Voigt D, Perez Goodwyn P, Sudo M, Fujisaki K, Varenberg M (2019) Gripping ease in southern green stink bugs Nezara viridula L. (Heteroptera: Pentatomidae): Coping with geometry, orientation and surface wettability of substrate. Entomol Sci 22(1):105-118

Vötsch W, Nicholson G, Müller R, Stierhof YD, Gorb S, Schwarz U (2002) Chemical composition of the attachment pad secretion of the locust Locusta migratoria. Insect Biochem Mol Biol 32(12):1605-1613

Wang J, Liang AP (2015) Ultrastructure of the fossula spongiosa and pretarsus in Haematoloecha nigrorufa (Stål) (Hemiptera: Heteroptera: Reduviidae: Ectrichodinae). Zootaxa 3963(2):230-239

Wiese K, Schmidt K (1974) Mechanorezeptoren im Insektentarsus. Die Konstruktion des tarsalen Scolopidialorgans bei Notonecta (Hemiptera, Heteroptera). Z Morph Tiere 79:47-63

Publisher's Note Springer Nature remains neutral with regard to jurisdictional claims in published maps and institutional affiliations. 